Portland State University

PDXScholar

1975

\title{
Self and Ideal-Self Concepts in a Prison Population: (1) Self and Ideal-Self Patterns of Violent and Non- Violent Offenders, (2) Self and Ideal-Self Concepts in Relation to Time Served Within a Prison
}

\author{
Alison Prince Berman \\ Portland State University \\ James W. Kushmuk \\ Portland State University
}

Follow this and additional works at: https://pdxscholar.library.pdx.edu/open_access_etds

Part of the Social Psychology Commons

Let us know how access to this document benefits you.

\section{Recommended Citation}

Berman, Alison Prince and Kushmuk, James W., "Self and Ideal-Self Concepts in a Prison Population: (1) Self and Ideal-Self Patterns of Violent and Non-Violent Offenders, (2) Self and Ideal-Self Concepts in Relation to Time Served Within a Prison" (1975). Dissertations and Theses. Paper 2289.

https://doi.org/10.15760/etd.2286

This Thesis is brought to you for free and open access. It has been accepted for inclusion in Dissertations and Theses by an authorized administrator of PDXScholar. Please contact us if we can make this document more accessible: pdxscholar@pdx.edu. 
AN ABSTRACT OF THE JOINT THESES OF AIison Prince Berman and James W. Kushmuk for the Master of Science in Psychology presented August $5,1975$.

Title: Self and Ideal-self Concepts in a Prison Population

(I) Self and Ideal-self patterns of violent and non-violent offenders.

(II) Self and Ideal-self concepts in relation to time served within a prison.

APPROVED BY MEMBERS OF THE THESIS COMMITTEE:

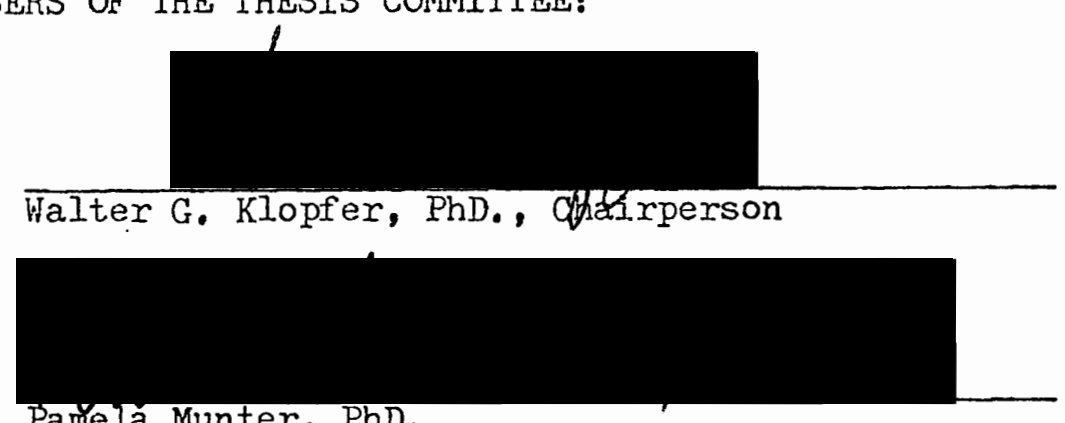

Pamela Munter, Phi.

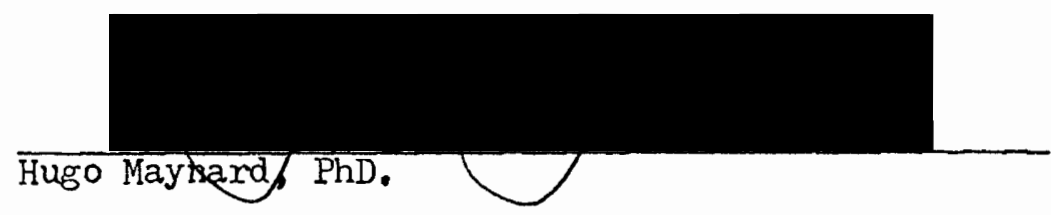

Two interrelated studies explored the self and ideal-self patterns, two important components of the total personality, of a male prison population using the Interpersonal Adjective Checklist (ICL). Both studies used the same prison subjects $(n=38)$, who were divided equally between violent and non-violent offenders. Study I also used a normative sample $(n=38)$ of male students. All subjects filled out two ICL forms, one with self and one with ideal-self instructions. Study I investigated the ICL patterns of the prsoners in terms of 
type of crime (violent vs. non-violent) and also compared the ICL scores of the prisoners (violent and non-violent) to the student group. No significant difference between the violent and non-violent prisoners were found for any of the thirteen ICL scores (the eight octant scores, DOM, LOV, Ain, Nic, and SID), for either self or ideal-self instruction sets. Several important differences between the prisoners and the nonprison group were found, however. Prisoners viewed themselves as possessing significantly less love (LOV score) and less managerial-autocratic behavior (AP) than the non-prison group, and had self-concepts which were less socially desirable (Ain score). Prisoners gave self-concepts which were significantly higher than the non-prison group on rebellious-distrustfulness (FG). For the ideal-self instruction set, prisoners scored significantly lower than the student sample on the octants measuring rebellious-distrustful behavior (FG) and self-effacing-masochistic behavior (HI) and significantly higher than the non-prison group on the Ain score, indicating a less socially desirable ego-ideal. It is concluded that prisoners, when compared to non-prisoners, have self-views which are marked by more hate and rebelliousness and ideal-self concepts which markedly limit such socially unacceptable traits.' The authors conclude that prisoners were being truthful in their self and ideal-self reports, but demonstrated that even if the prisoners were lying, useful information can be obtained from the ICL data. / Study II investigated the relationship between length of imprisonment and the ICL self and ideal-self patterns of the prisoners. Correlations between length of time already served and each of the thirteen ICL scores were performed for both self and ideal instruction sets (with the effects of type of crime factored out). For self 
scores, significant negative correlations were found between length of imprisonment and the ICL scores measuring love (LOV), cooperative-overcontrol behavior (IM), docile-dependent behavior (JK), and self-effacingmasochistic behavior (HI). For the ideal-self, there was a significant negative correlation between time and love (IOV) and a significant positive correlation between time and the ICL score measuring aggressive-sadistic behavior $(D E)$. It is concluded that prisoners come to view themselves as more hateful and less cooperative and friendly as they spend more time within the confines of the prison. Prisoners also tend to adopt ideals which are marked by hatefulness and hostility as they spend more time in prison, indicating the existence of a prisonization process. The results point to the negative impact imprisonment has on one's self-conception and values.

The two interrelated studies comprising this research demonstrate that the ICL, a device used mainly for clinical diagnosis, is also a research tool in that it provides relevant and insightful information about the interpersonal dynamics of a group of prisoners. It is suggested that the ICL be used more frequently to study the self and ideal-self concepts of prisoners as well as other types of groups. 
SELF AND IDEAL-SELF CONCEPTS IN A PRISON POPULATION

(I) Self and Ideal-self patterns of violent and non-violent offenders.

(II) Self and Ideal-self concepts in relation to time served within a prison.

\title{
by
}

ALISON PRINCE BERMAN \& JAMES W. KUSHMUK

Joint theses submitted in partial fulfillment of the requirements for the degree of

\author{
MASTERS OF SCIENCE \\ in \\ PSYCHOLOGY
}

Portland State University

1975 
TO THE OFFICE OF GRADUATE STUDIES AND RESEARCH:

The members of the Committee approve the joint theses of

Alison Prince Berman and James W. Kushmuk presented August 5, 1975.
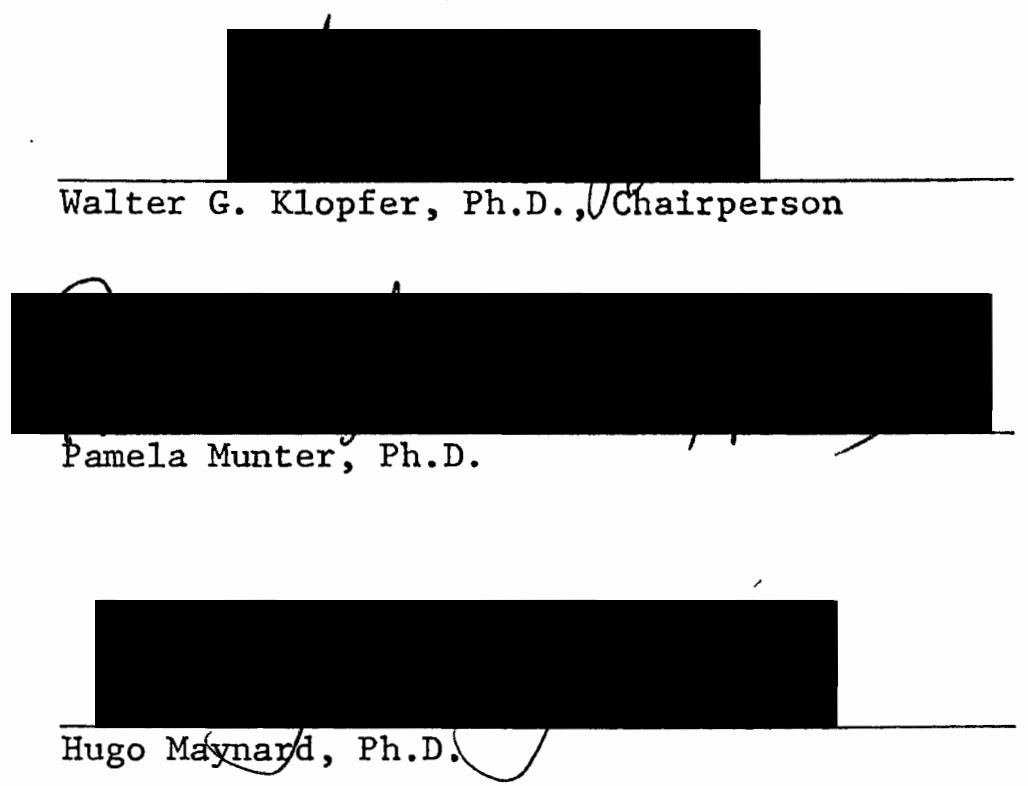

APPROVED :
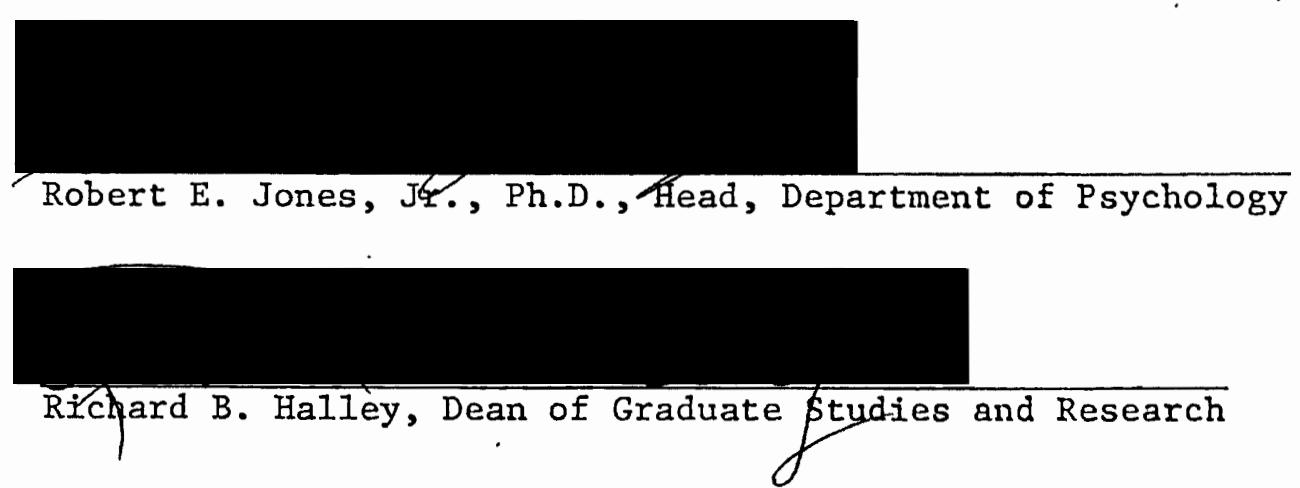

August 5, 1975 


\section{ACKNOWLEDGEMENTS}

Many people have been invaluable to us in the writing of this thesis. Our warmest thanks and appreciation are due our committee: Dr. Walter Klopfer, our chairperson, whose ideas inspired us to do this thesis and whose insights and advice have been most helpful; Dr. Pamela Munter, whose comments, editing, and support were essential; and Dr. Hugo Maynard.

The authors wish to express theix appreciation to our friends, David Leitner and Christine Bauman, who helped us during the initial stages of our project. We would also like to thank Jim Paulson for statistical guidance, and Alice Heiser for her efforts in helping us get people together. We are particularly grateful to Steve Glassner, the inmates at the Oregon State Penitentiary, and Barbara Mecca's psychology students of the Spring term, 1975. Lest we not forget our spouses, Paul Berman and Wendy Millex for theix contributory thoughts and cooperation.

This thesis is dedicated in the hope that the knowledge gained from our research will be useful in prisoners getting to know themselves and in rehabilitators getting more insight into the prisoners they serve. 
TABLE OF CONTENTS

PAGE

ACKNOWLEDGEMENTS

CHAPTER

I INTRODUCTION $\ldots \ldots \ldots \ldots \ldots \ldots \ldots \ldots \ldots \ldots \ldots \ldots \ldots \ldots$

II STUDY I: SELF AND IDEAL-SELF PATTERNS OF VIOLENT AND NON-VIOLENT OFFENDERS

6

III STUDY II: SELF AND IDEAL-SELF CONCEPIS IN RELATION TO TIME SERVED WITHIN PRTSON .............

IV METHODS AND PROCEDURES $\ldots \ldots \ldots \ldots \ldots \ldots \ldots \ldots \ldots \ldots$

Subjects $\quad \ldots \ldots \ldots \ldots \ldots \ldots \ldots \ldots \ldots \ldots \ldots \ldots \ldots \ldots$

Measuring Instrument $\ldots \ldots \ldots \ldots \ldots \ldots \ldots \ldots \ldots$

Design of study $I$..................... 26

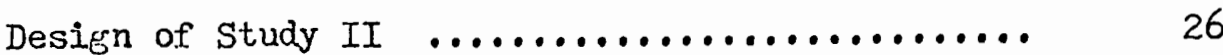

Procedure $\quad \ldots \ldots \ldots \ldots \ldots \ldots \ldots \ldots \ldots \ldots \ldots \ldots \ldots \ldots \ldots \ldots \ldots . . \ldots$

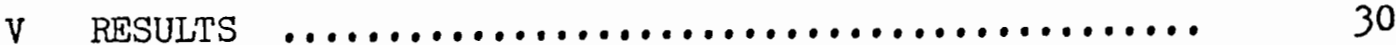

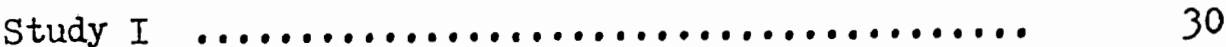

Study II $\ldots \ldots \ldots \ldots \ldots \ldots \ldots \ldots \ldots \ldots \ldots \ldots \ldots . . \ldots \ldots$

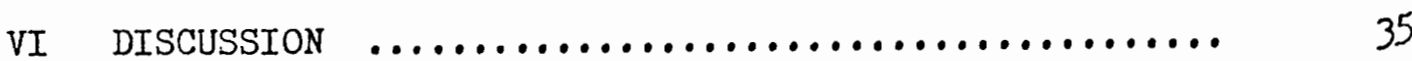

Study $I \quad \ldots \ldots \ldots \ldots \ldots \ldots \ldots \ldots \ldots \ldots \ldots \ldots \ldots \ldots \ldots \ldots . \ldots \ldots \ldots$

Study II $\ldots \ldots \ldots \ldots \ldots \ldots \ldots \ldots \ldots \ldots \ldots \ldots \ldots \ldots . \ldots \ldots \ldots$

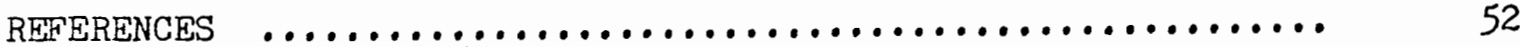


APPENDICES $\quad \ldots \ldots \ldots \ldots \ldots \ldots \ldots \ldots \ldots \ldots \ldots \ldots \ldots \ldots \ldots \ldots \ldots \ldots \ldots$

A. ICL GRID $\ldots \ldots \ldots \ldots \ldots \ldots \ldots \ldots \ldots \ldots \ldots \ldots \ldots \ldots \ldots \ldots \ldots \ldots \ldots \ldots \ldots$

B! CLASSIFICATION OF CRIMES $\ldots \ldots \ldots \ldots \ldots \ldots \ldots \ldots \ldots$

C. INTERPERSONAL CHECKLIST $\quad \ldots \ldots \ldots \ldots \ldots \ldots \ldots \ldots \ldots \ldots \ldots$ 


\section{IIST OF TABLES}

\section{TABLE}

I ICL Mean Scores for Violent and Non-violent

Prisoners $\quad \ldots \ldots \ldots \ldots \ldots \ldots \ldots \ldots \ldots \ldots \ldots \ldots \ldots \ldots$

II ICL Mean Scores for Prisoners and Non-Prisoners ......

III Partial Correlations of Length of Imprisonment by

ICL Scores 


\section{CHAPTER I}

\section{INTRODUCTION}

This research was an exploratory investigation of the self and ideal-self concepts of a male prison group with a device which measures personality on interpersonal dimensions. The Interpersonal Adjective Checklist, (ICL), seemed best suited for tapping these two levels of persoriality of criminal offenders, a group which has indeed met with difficulties in interpersonal relationships.

Universally speaking, personality is what characterizes an individúal; "the sum total of the ways in which an individual characteristicanly reacts to and interacts with others" (Ferguson, 1970, p. 2). Personality has been defined in many ways and in turn has been studied according to several different theories. Most theories have one thing in common - they use the term trait to define personality (Silverman, 1971). "A trait is a particular and persistent feature of an individual's personality - a characteristic that can be measured and observed" (Silverman, 1971, p. 495).

One definition of personality tells us that each person tends to determine his own personality by what he thinks of himself. Based on past experiences, his self concept identifies him to himself as shy or aggressive, frlendly or unfriendly, dominant or submissive and so on. Thus, if the individual considers himself aggressive, he will then behave aggressively, be known to others as aggressive and thus himself if that is how he interprets this behavior (Silverman, 1971). 
The present researchers believe that there exists a self concept and that it is a social product. Interpersonal events influence the development of certain personality characteristics. Thus, our personalities are constantly emerging and stimulated by various interpersonal events which are experienced by an individual (Silverman, 1971).

To talk of a person's personality is to try and envision something of his essence as a human being. These constitute his traits or characteristics, what he typically does or says or his beliefs. And if we probe deeply into a personality, there exists at the core, a person's self concept (Royce, 1964).

Many who theorize about the development of self concept agree that this most personal aspect of our human nature is a product of our social interaction with others (Zimbardo, 1975). The idea of a self concept is not new. In 1902, Charles Cooley proposed a "looking glass șelf" that reflected what we imagine others hold of us (Zimbardo, 1975). George Herbert Mead extended this notion and asserts that our self concepts develop from orientations others have toward us which we take on as our own percepts (Zimbardo, 1975). For William James there are three components of the self and of the three, the social self holds that we form a concept of ourselves the way we imagine our image to be in the minds of others (Zimbardo, 1975).

Thus, there exists a self concept; the perceived present behavior of the individual which he wishes to communicate, which is a determinant of personality.

An equally important component of personality is the person's idealized self. As Kluckholn and Murry (1949, p. 21). point out: "One 
of the important establishments of personality is the ideal self, an integrate of images which portrays the person 'at his future best', realizing all his ambitions." Carl Rogers (1959) uses the self as a starting point in his theory but works toward the ideal-self. "Behavior is the goal-directed attempt of the organism to satisfy the experienced needs for actualization in the reality as perceived" (1959, p. 22). Research has demonstrated the existence of self and ideal-self concepts (Leary, 1957) and that these concepts are indicators of differences in individuals (Bieri \& Lobeck, 1961; Rulla \& Maddi, 1972; Hartung et al, 1971; Berg, 1974; Baugham \& Pierce, 1972).

The premise that self and ideal-self concepts are important components of the total personality means that the study of these two factors can be accomplished within a broader system of personality. There are a multitude of personality theories within psychology, and one way of dividing them is into inter-personal and non-interpersonal types (Leary, 1957). An interpersonal system of personality is one which stresses the individual-in-relation-to-others. Such a system views the individual as essentially a social being who is affected by the external forces created by other individuals. Theories such as those of Karen Horney, Erich Fromm, and Harry Stack Sullivan are good examples of what Leary means by interpersonal theories. As Leary (1957) points out, all three of these theorists view anxiety reduction as the motivating factor of personality, and all agree that anxiety is an interpersonal phenomenon, having its basis in the fear of rejection by others. In contrast to such interpersonal theories are the more traditional non-interpersonal systems which emphasize nonsocial aspects of the individual. Freudian 
theory, which looks at personality in relation to instinctual drives and uses a terminology which stresses the individual as an isolated unit, Is the classic example of a non-interpersonal personality system.

The present research has investigated self and ideal-self concepts of criminal offenders within an interpersonal framework; specifically, within the system of personality evaluation outlined by Timothy Leary In his work, Interpersonal Diagnosis of Personality (1957). Leary defines interpersonal behavior in the following way: "Behavior which is related overtly, consciously, ethically, or symbolically to another human being (real, collective, or imagined) is interpersonal" (1957, p. 4). He has devised a system where personality is evaluated in terms of sixteen interpersonal behavior types which can be paired to make up eight interpersonal variables. Each of the eight pairs represents an interpersonal style, with one member of the pair representing the moderate or adaptive level of the behavior and the other signifying the intense or maladaptive level. The elght variables are arranged in a circular grid (See Appendix A) defined by two dimensions: love-hate (horizontal dimension) and dominance-submission (vertical).

Leary's system of personality assessment employs a multi-level approach, where personality is evaluated on the following five levels: the level of public communication (I), the level of conscious perception (II), the level of private symbolization (III), the level of the unexpressed unconscious (IV), and the level of values and goals (V).

The present research has investigated the personality of criminal offenders on levels II and V. Level II, the level of conscious communication, is a measure of how the individual chooses to present himself; 
It is the level of conscious self-report which deals with the surface meaning of what the person says about himself. The unit of measure for level II is the interpersonal attribute or trait. Level $V$, the level of values or the ego ideal, is simply the individual's consciously reported ideal-self. It is a measure of the person's interpersonal value system of how he would like to be, of what he views as right and good. Specifically, the authors of this research have studied the self and ideal-self concepts of prisoners in two interrelated studies:

Study I: "Self and Ideal-self patterns of violent and non-violent offenders."

Study II: "Self and IdeaI-self concepts in relation to time served within a prison." 


\section{CHAPTER II}

\section{STUDY I: SEIF AND IDEAL-SELF PATTERNS OF VIOLENT AND NON-VIOLENT OFFENDERS}

There has been much research into the personality characteristics of prisoners. The study of crime and personality is not new. Man has throughout history attempted to explain the criminal, the deviant, through philosophical, religious, and mystical explanations. In the 19th century an Italian anthropologist, Lombroso, proposed that there exists a criminal type recognizable by various physical abnormalities (Eysenck, 1964). Thus, the road was open and on it walked many physicians, anthropologists, sociologists and psychologists hoping to shed some light on the criminal - the "caged" man; who he was and why.

Megargee and Mendelsohn (1962), using the MMPI concluded that the criminal population is significantly different from "normals". A group of studies (Brenberg, 1960; Giannell, 1966) using the Edwards Personality Preference Schedule (EPPS), an instrument which measures 15 independent narmal need variables, have found that prisoners (as compared to a normative sample) have a higher perceived need for deference, order, abasement, and endurance and a lower perceived need for exhibition and dominance. This means that offenders need:

to get suggestions from others, to find out what others think, to praise others, to accept the leadership of others, to let others make decisions.....to feel guilty when one does something wrong, to accept blame when things do not go right, to feel that personal pain and-misery suffered does more good than harm, to feel 
the need for punishment for wrong doing; to feel inferior to others in most respects (Brenberg, 1960, 320-321).

On the other hand, prisoners do not need: "to say witty and clever things, to talk about personal achievements, to be the center of attention .... do not need to be dominant" (1960, p. 322).

Gynther and McDonald (1961) studied the personality characteristics of prisoners, psychiatric patients and student nurses as depicted by the Leary system. They found that the personality characteristics for the institutionalized group differs from the "normal" group. Underlying narcissism and hostility was found among the prison group.

Eysenck and Eysenck (1971) compared male criminals to male trainee railmen on three dimensions of personality: Psychoticism (P) Extroversion (E) and Neuroticism (N). H.J. Eysenck is one of the forerunners in the area of crime and personality. Based on Pavlov's concept of conditioning he developed a theory of crime causation in which he states that extroverts condition poorly and that delinquents are more extroverted than non-delinquents. It follows, then, that delinquents will condition poorly. The very lack of conditionability would greatly influence the way people develop, as socialization is mediated by a process of conditioning. Eysenck (1964) defines extroversion by intercorrelating observed personality traits. He finds the typical extrovert to be:

sociable, likes parties, has many friends, needs to have people to talk to, craves excitement, takes chances, acts on the spur of the moment, generally impulsive, carefree, easy-going, optimistic, tends to be aggressive, loses his temper quickly, and not always a reliable person (Eysenck, 1964, p. 36). 
Eysenck and Eysenck (1971) found that prisoners were significantly higher on $\mathrm{P}$ and $\mathrm{N}$, but lower on $\mathrm{E}$. This finding is supported by Hoghught and Forrest (1970), who found young male offenders to be more introverted than extroverted when compared to a normative sample. Further research by Eysenck and Eysenck (1971), however, has shown that the items measuring the sociability component of $E$ are not positively related to criminality and that it is the "impulsiveness" aspects of $E$ which may be associated with criminal behavior. Thus, the findings obtained used only $E$ items related to sociability which accounts for the negative $E$ score. Eysenck's extroversion theory has been supported by Buikhuisen and Hemmell (1972) and recently in a study comparing male recidivists with trainee bus drivers (Wilson and Maclean, 1974). The authors found the criminals to be more psychotic, extroverted and neurotic than controls (1974).

Pishkin and Thorne (1973) compared incarcerated felons to college students on a 200 item questionnaire that measures subjective existential $s$ tate reactions to the state of being at any point in life. According to these researchers,

subjective reactions to one's state of Being at any point in life are reflected in conscious self concepts and that states of existential morale or demoralization are prime determinants of behavior on the highest integrative levels (1973, p. 392).

In other words, the college students demonstrated above average ratings on dependent religiousity, high morale, concem over the human condition, with lowest ratings in self-concept and philosophical optimism. On the other hand, the incarcerated prisoner rated only slightly above average on factors of demoralization state/existential neurosis, religious 
dependency defenses, existential confidence/morale, self-actualization esteem and below average on concern over the human condition. They expressed views indicating that the world was going to hell, how dangerous life is getting, that they have had it and want to be alone in peace. High demoralization was expressed as well by the prison group, manifested by feelings of self-hate, the unbearableness of life, feelings of being passed by and being a failure. Similarly, Fitts (Fichtler, Zimmermann and Moore, 1973) developed a self-concept measurement instrument (the Tennessee Self-concept Scale) and with it (Fitts and Hammer, 1969) concluded that prisoners have a lower opinion of themselves as compared to non-prisoners as the prisoner perceives himself as inadequate, morally bad, ethically bad and worthless.

The literature then, has depicted a distinct difference between male "normals" and male criminals with respect to personality characteristics.

Now that it has been established that there exists a criminal population with its own unique characteristics, a further review of the Iiterature would serve to define even more preclsely those personality traits common to the public offender.

The MMPI, a widely used and respected personality assessment technique, has been used in many studies to tap at the personality characteristics of the prisoner (Godfrey, 1971; Baugham and Pierce, 1972; Dahlstrom, Welsh and Dahlstrom, 1972; Kodman and Hopkins, 1970; Gynther and McDonald, 1961; Megargee, Cook and Mendelsohn, 1967; Blackburn, 1968; Megargee and Mendelsohn, 1962; Davis and Sines, 1971; Carroll and Fuller, 1971). By using the MMPI with both self and ideal-self instruc- 
tions, Baugham and Pierce (1972) showed that prisoners are able to distinguish between their conception of self and ideal-self. The difference between the self and ideal-self concepts on the MMPI was more of a difference of elevation (the discomfort and distress being experienced by the prisoner) than of configuration (a combination of factors from different scales) (1972). Berg (1974) studied the self-concepts of two groups within a prison population based on both MMPI files and clinical interviews: the neurotic and sociopathic. Through the use of the Chicago Q-sort, Berg (1974) found that both groups expressed similar ideal concepts but differed significantly for their self-concepts. "The neurotics described themselves as nervous, anxious, high-strung, immature, hurried, and worrying. The sociopathic of fenders described themselves as daring, adventurous, clear-thinking, outspoken, warm-hearted, and unselfish" (1974, p. 622). Through the use of the MMPI it was also found that the personality of the prisoner is marked by an elevated Pd scale indicating hostility and aggressiveness in interpersonal relationships, irritability and self-disssatisfaction (Kodman and Hopkins, 1970; Dahlstrom, Welsh and Dahistrom, 1960; Davis and Sines, 1971). Other scale elevations have emerged. Godfrey (197I) indicates in his study of the "average offender" that elevated $D$ and $S c$ scales demonstrate the offender's impulsivity and tendency to be mildiy deviant and also concludes that the MMPI profile suggests suspicious and distrustful trends and the inability to delay gratifications in the offender. Common MMPI scale configurations have also been studied. David and Sines (1971) studied the MMPI patterns of three clinical groups and found the Pd-Hy configuration common among prisoners exhibiting hostile-aggressive acting out. The authors concluded: 
If one's primary aim is to discriminate all assaultive men from non-assaultive men, this particular MMPI pattern described will be of limiting value. The MMPI prototype described here does, however, possess a high degree of validity in that hostile-aggressive behavior is a regularly noted characteristic of men who generate this profile pattern (1971, p. 232).

Kodman and Hopkins (1970) found a Pd-Ma peak common to their prisoners tested indicating overreactivity, irritability, talkativity, stubbornhostility and dissatisfaction with interpersonal relations. Surveys carried out by Sheldon and Eleanor GIueck (Eysenck, 1964) have found the main personality traits of criminals to be "restlessly energetic, impulsive, extroverted, aggressive, destructive and highly emotional" (Eysenck, 1964, p. 131).

Thus, there appears to be confirmed some common and distinctive traits to be assigned to the prison group and in short, the research indicates in general, that prisoners tend to be hostile, impulsive, overreactive and with a tendency toward suspiciousness and distrustfulness. Researchers have not only looked at the way prisoners differ from non-prisoners, but have also attempted to classify them according to a number of variables (Berg, 1974; Megargee and Mendelsohn, 1962; Megargee et al, 1967; Blackburn, 1968; Carlson, 1972; Caxroll and Fuller, 1971; Hom, 1956; Lester et al, 1974; Yarvis, 1972/73).

Yarvis (1972/73) has classified criminal offenders through the use of current psychoanalytic concepts, while Perdue and Lester (1974) explored the personality of criminals, mainly murderers, based on differences of race. Berg (1974) in his study of the self-concept of criminal offenders, divides his group into two commonly identified classifications: neurotic and sociopath. Carlson (1972) using the Differentiated Personality 
Inventory (DPI), self-rating scales and a vocabulary test, divided prisoners into various classes according to how they cluster in terms of their assessment devices. They were able to categorize their subjects in terms of twelve classes. However, these twelve categories were insensitive in terms of making distinctions between different criminal types. Some researchers have found that there is little difference among different types of offenders when the Edwards Personality Preference Schedule (EPPS) is used (Giannell, 1966) and with the MMPI (Megargee and Mendelsohn, 1962; Megargee et al, 1957). Still, others have classified prisoners according to the different types of criminal offenses (Glover, 1960) and further divided this group specifically into violent and non-violent offenses (Wilds, 1973; Megargee et al, 1967; Megargee and Mendelsohn, 1962; Davis and Sines, 1971; Carroll and Fuller, 1971).

Prisoners have been classified into violent and non-violent groups according to the crime committed, but the offenses are often deleted from the study (Carroll and Fuller, 1971) or the list of crimes is incomplete (Megargee and Mendelsohn, 1962). Wilds (1973) appears to have the most complete classification of crimes committed, defined into the two groups of violent and non-violent. Three independent judges classified convicted prisoners into categories of violent and non-violent.

Violence was defined as naked aggression - hostility translated into physical action that has the intent to cause harm to people or destruction to property. Violence, by definition, may be actual or potential. One may assault or threaten his victim (1973, p. 427).

It is to this classification group, violent and non-violent, that we focused our attention, as the present researchers were interested in 
exploring the personality patterns (the self and ideal-self concepts) of a group of prisoners by type of crime. Wilds' classification system of violent and non-violent crimes was used in this study (See Appendix B).

Few studies have looked into the distinct characteristics of these two groups. When the MMPI is used there is contradictory evidence as to whether or not personality differences exist (Megargee and Mendelsohn, 1962; Megargee et al, 1967). Using groups known to differ on traits of hostility, impulsivity and control, Megargee and Mendelsohn (1962) studied assaultive acting out in relation to the MMPI scales of prisoners. Any scale of hostility and control should be able to discriminate between highly aggressive criminals (violent) and non-violent ones. Murder, manslaughter, assault with a deadly weapon constituted the extremely assaultive group (Group I). The non-assaultive crimes consisted mainly of burglars (Group III). Group II was made up of moderately assaultive crines (Battery). None of the scales were able to discriminate among the three different criminal groups. However, the Hy scale appeared promising as Groups I and II were significantly higher on this scale than Group III. Hy-5 (Inhibition of Aggression) significantly differentiates I and II from III. Assaultive criminals were found to score higher on inhibition of aggression than non-assaultive criminals. The less assaultive, the more under-controlied and hostile. The authors conclude: Certainly the data indicate it is difficult if not impossible to identify an assaultive individual with reasonable accuracy using the MMPI scales now available (1962, p. 437).

That the Hy scale appears promising is further supported by the fact that the Pd-Hy scale configuration is somewhat valid for predicting 
hostile criminal behavior (Davis and Sines, 1971).

The MMPI has been said to be unsatisfactory for differentiating between various prison groups (Megargee and Mendelsohn, 1962; Megargee et al, 1967). However, Carroll and Fuller (1971) investigated prisoners manifesting different committed crimes to see whether the MMPI could adequately differentiate between a non-violent, violent and sex offender group. Carroll and Fuller (1971) point out that the literature suggests that the non-violent group consists of individuals exhibiting a passive aggressive personality. Those in the violent group exhibit an aggressive personality while those in the sexual group are dependent and insecure. When age blas was controlled, the non-violent group differed from the violent and sexual group on three MMPI personality scales (F, Sc, Ma). The non-violent group exhibited the most deviant personality profile (1971).

Among hostile-aggressive criminals there seem to be two types: overcontrolled-hostile and undercontrolled-hostile. Megargee et al. (1967) have developed an MMPI scale called 0-H (overcontrolled-hostility) which can distinguish with some success the two types. The 0-H groups are theorized by Megargee to be more prone to "bursting out" their aggressions which become pent up by committing extremely assaultive crimes (homicide) than the undercontrolled-hostility type. This theory has been validated by Blackburn (1968) who found that extremely assaultive criminals are more overcontrolled, introverted, conforming and less hostile than moderately assaultive criminals.

Others have studied particular criminal groups engaged in violent and non-violent offenses. Robbers were found to be higher than burglars 
on need-aggression when using the EPPS (Horn, 1956). Through the use of this same test, it was found that rapists and murderers tend to be less aggressive, less independent, less assurant and dominant and more self critical (Howell, 1972/73). According to Abrahamsen (1973) the prime marks of the murderer are "Helplessness, impotence, nagging revenge, irrational hatred for others, suspiciousness, self-centeredness, lack of self-esteem" (1973, p. 13) .... "blurred image, suggestable, impressionable" (1973, p. 12) .... "withdrawn and calculating" (1973, p. 14). In contrast to the more violent criminal, the non-violent offender (burglars, for example) is furtive. According to Bromberg (1948) passivity is the underlying characteristic of burglary and the basic characteristic of burglary is stealth - "the aggression of a passive individual with a feeling of inferiority" (1948, p. 141). "In some burglars, submissiveness is not easily recognized as a basic personality trait" (1948, p. 141). Often, the attitude of the captured young offender is seen as aggressive due to the surface facade of the individual.

Thus, for the violent groups that have been studied, there exists an aggressive personality marked by dependence, dominance, self-centeredness and overcontrol. On the other hand, non-violent groups are less controlled, more passive in their aggression and manifest more deviant MMPI profiles.

There appears to be little significant investigation into the idealself concepts of these two groups. For these very reasons, the ICL has been chosen to investigate the patterns (self and ideal-self concepts) of the violent and non-violent prisoners. Still further, the ICL has been demonstrated to be a good measure of self and ideal-self concepts 
with various psychiatric and non-psychiatric groups (Leary, 1957; Hartung et al, 1971; Bieri and Lobeck, 1961; Rulla and Maddi, 1972). There also exists a relation between the ICL and other personality assessment tools. Leary (1957) found the ICL octants to be related to various MMPI scales. Similarly, there exists a relation between the EPPS, which provides scores on different independent need variables, and the ICL (Gynther et al, 1962). "Significant systematic relationships were found between scores on the two tests, suggesting direct and predictable relations" (1962). "For example, it was predicted and confirmed that the ICL Love variable is positively associated with EPPS needs Affiliation and Nurturance and negatively associated with needs Autonomy and Aggression" (1962, p. 451).

Thus, the ICL appears capable of justifying interpretations from other personality tests and may be found to support and even be a better indicator of the characteristics of an individual's personality. Furthermore, the ICL has rarely been used in prison research.

This research, being exploratory, examined a wide range of ICL patterns. Select hypotheses were made however, about several of the ICL scores:

1. The self-concepts of the non-violent prisoners would be characterized by passive-aggressiveness (Carroll and Fuller, 1971; Bromberg, 1948) while the self-view of the violent criminals would be marked by dominant-aggressiveness.

2. The violent offender would have a self-concept which is higher on dominance (DOM) and lower on love (LOV) than the non-violent offender. 3. The non-violent group would respond in less soclally desirable 
ways than the violent group (Carroll and Fuller, 1971).

4. Prisoners as a group would obtain higher self-concept scores on Aggressive-Sadistic and Rebellious-Distrustful octants than the nonprisoners. There would be a tendency for the prison group to be higher on the Competitive-Narcissistic and Self-Effacing-Masochistic octants.

5. The self-descriptions of the prison group would be characterized by less love (LOV) and less dominance (DOM) than the non-prison group.

6. The prisoners would tend to describe themselves in a less socially desirable fashion than the non-prison group. 
CHAPTER III

\section{STUDY II: SELF AND IDEAL-SELF CONCEPTS IN RELATION TO TIME SERVED IITHIN PRISON}

Self and ideal-self concepts are by no means completely stable aspects of personality. How a person views him or herself as well as his or her values will undoubtedly undergo alteration as a result of profound changes in the normal life pattern. Entering a prison marks a very radical change in life style, and so it is reasonable to assume that the experience of being imprisoned will affect self and ideal-self concepts. Much theorizing has been done in the past few decades as to the effects of institutionalization on personality and behavior, and two recurring names in this area are Erving Goffman and Donald Clemmer.

Erving Goffman has done extensive work in exploring the characteristics of "total institutions" and how they affect the personality. Goffman (1961) describes the total institution in the following way:

Their encompassing or total character is symbolized by the barrier to social intercourse with the outside and to departure that is often built right into the physical plant, such as locked doors, high walls, barbed wire, cliffs, water, forests, or moors " (p. 4).

When a person enters a total institution such as a prison, the conception he has of himself is suddenly disrupted by a set of experiences which are inconsistent with his pre-institutional view of the world. The following description of the inpatient phase in a mental hospital applies equally well to prisons: 
Like the neophyte in many of these total institutions, the new inpatient finds himself cleanly stripped of many of his accustomed affirmations, satisfactions, and defenses and is subjected to a rather full set of mortifying experiences: restriction of free movement, communal living, diffuse authorIty of a whole echelon of people, and so on. Here one begins to leam about the limited extent to which a conception of oneself can be sustained when the usual setting supports for it are suddenly resolved (Goffman, 1961, p. 148).

The pre-institutional self thus loses importance when one enters such a restrictive environment and a new institutional self is created, which, according to Goffman, is marked by feelings of personal failure.

Along the same lines of Goffman's theory is Donald Clemmer's Idea. of "prisonization" (clemmer, 1959). Whereas Goffman is interested in the self-view and how it is affected by institutionalization, clemmer is concermed with how one's values undergo alteration as a result of imprisonment. Clemmer proposes "prisonization" as a process by which the inmate, as he begins to associates closely with other prisoners upon entry, begins to accept a set of values which tend to deepen criminality and anti-sociality. Prisonization is a process of assimilation; the newly arrived inmate, as he begins to penetrate the new culture, internalizes the values and sanctions of that culture. The extent of prisonization depends upon the specific characteristics of the institution and the individual, but Clemmer belleves that prisonization will occur to some degree to anyone who enters prison. He has proposed "universal factors of prisonization" (Clemmer, 1959) which are operative for all who are forced to become part of the prison society. The six universal factors are: (1) acceptance of an inferior role, (2) accumulation of knowledge of prison organization, (3) new eating, working, and dress habits, (4) adoption of the prison language, (5) realization that nothing is 
owed to the environment for supplying the needs of life, and (6) desire for a good job. If nothing else does, these six factors common to all prison experiences will change the personality and values of the prison inmate.

Taken together, the theories of Goffman and Clemmer suggest that both the prisoner's self-concept and values are changed as a result of institutionalization. Thus, time spent within the prison should be an important factor. The major purpose of this study was to investigate if a relationship between length of imprisonment and self and ideal-self concepts as measured by the ICL does exist for prisoners convicted of violent and non-violent crimes.

Goffman, Clemmer, and others (Cressey, 1961; Sykes, 1958) have hypothesized as the the effects of incarceration on personality, selfconcepts, and values, but relatively little research has been done in this area. Two direct attempts have been made to test clemmer's theory of prisonization, and the results of these two studies are not in agreement. The earlier of the two was performed by Wheeler (196I) who found support for prisonization. Wheelex studied the values of his prison population in terms of conformity to staff expectations by having both prison inmates and staff answer a questionnaire asking how one should behave in five hypothetical conflict situations. By comparing inmate to staff responses, an index of conformity was obtained for each of the prison subjects. Wheeler looked at the degree of conformity as a function of time spent in prison. He found support for clemmer's theory; that is, there was a positive relationship between degree of nonconformand length of imprisonment as well as a positive relationship between 
degree of prisonization (or noncomformity to staff expectations) and the extent of involvement with the prison culture and other inmates. Wheeler also looked at his results in terms of the institutional phase of the prisoner, defining the early phase as those who had served less than six months, the middle phase as those who had served more than six months and had more than six months left, and the late phase as those who had less than six months left to serve. He found that conformity to staff expectations was relatively high in the early phase, dropped in the middle phase, and became elevated again in the late phase. Thus, prisonization, when looked at in terms of institutional career, exhibits an inverted U-shaped function, rising through the middle phase and dropping down as the late phase is reached. Wheeler concludes that the theory of prisonization works as a description of change over time, but that it is inadequate when prisoners are classified by phases of their institutional career.

Atchley and McCabe (1968) attempted to replicate Wheeler's findings, but obtained contradictory results. They performed an exact replication of Wheeler's methodology on prisoners from a different population and found that there was no significant relationship between length of incarceration and the degree of prisonization (measured as nonconformity to staff expectations). Atchley and McCabe conclude that Clemmer's and Wheeler's theories concerning the development of prisonization need to be researched further before any definite conclusions can be made. Goffman's theories as to the effects of institutionalization on one's self-concept have not been subjected to any direct investigation as Clemmer's theories have, but some of the reasearch on the self-esteem 
of prison inmates and other institutionalized individuals is relevant. Fichtler, et al (1973) studied the self-esteem of a prison group as a function of time served using the Butler-Haigh self-referent items, with self and ideal-self instruction sets. Self-esteem was measured as a discrepency score between the characteristics the subject viewed himself as possessing and the attributes that he would like to have 1deally. A high discrepency score, reflecting low self-esteem, is obtained when the subject views himself as possessing characteristics which he does not wish to have; a low discrepency score, indicating high self-esteem, results when the person sees himself as having characteristics which are very desirable. Self-esteem was studied in this manner across four groups: newly-arrived male prisoners, maximum-security male prisoners, a control group made up of college freshmen (males and females), and a rural, Protestant church group (both sexes also).

Fichtler, et al (1973) found that the distribution of self-esteem scores of the newly-arrived prisoners approximated that of the college student group, while the rural church group exhibited exceptionally high levels of self-esteem. The maximum-security prison group (which consisted of subjects who had all spent at least one year in prison) exhibited the lokest level of self-esteem. Furthermore, it was found that among the maximum-security prisoners, there was a significant positive correlation between discrepency scores (where a high discrepency score reflects low self-esteem) and time spent within the prison. These findlings are consistent with the results of an unpublished study by Fiedler and Bass (reported by Glasser and Stratton, 1961), who found that both non-confined and confined criminal offenders showed lower 
self-esteem scores than a non-prison group.

Tittle (1972) studied the effects of living within a Federal hospital, occupied by volunteer and imprisoned narcotic addicts of both sexes, on the level of self-esteem. The hospital possessed characteristics similar to a minimum-security prison, and $61 \%$ of its patients reported that they felt more like captives in a prison than patients in a hospital. Self-esteem was measured as the ratio of positive to negative items endorsed on a self-descriptive Q-sort task. The factor of time spent within the hospital was investigated, and it was found that Iiving within such an environment does have a negative impact on the level of self-esteem.

There is one other study of relevance by Bannister, et al (1973) which investigated the psychological effects of long-term imprisonment in British penal institutions. They administered a battery of tests, including the Eysenck Personality Inventory, the Sixteen-Personality Factor Questionnaire, the Hostility and Direction of Hostility Questionnaire, and the masculinity-femininity scale of the Californai Psychological Inventory to male prisoners serving indeterminate sentences or determinate sentences of ten years or more from various prisons throughout England. Four groups differing in total length of accumulated imprisonment were tested. It was found that hostility, especially hostility directed towards the self, and introversion increased significantly with total length of accumulated imprisonment. The authors concluded that spending time within prison does have a detrimental impact on the personality of criminal offenders. Aside from the Bannister, et al (1973) study and the studies of self-esteem, there is no other relevant research on the 
personality and self/ideal-self concepts of incarcerated criminals and how they are changed as a result of time spent within prison.

In conclusion, there is evidence suggesting that the conception a person has of himself is altered by living within what Goffman calls a total institution. The research findings suggest that living within an institution is associated with: (I) increased levels of self-directed hostility and introversion (Bannister, et al. (1973), (2) a tendency to view the self in more negativistic terms (Tittle, 1972). No definite conclusions can be drawn from the contradictory results of wheeler (1961) and Atchley and McCabe (1968) as to whether or not an individual's values change as a result of prisonization, as clemmer has proposed.

This study investigated the self and ideal-self patterns over a wide range of ICL scores. Hypotheses about several of these scores were made, based upon the literature reviewed:

1. For ideal-self concept scores, length of imprisonment would be negatively correlated to Love as measured by the ICL (IOV).

2. For the ideal-self, length of imprisonment would be associated with a decreased level of social desirability of response, as measured by the Ain score. Since a high Ain score reflects a low level of social desirability, a positive correlation was predicted between Ain and time.

3. For the self-concept, length of imprisonment would be positively correlated to the ICL octant score measuring self-effacing-masochistic behavior (octant HI). 


\section{CHAPTER IV}

\section{METHODS AND PROCEDURES}

Subjects. Forty male prison inmates from the State Penitentiary in Salem, Oregon were tested. Thirty-eight of these subjects were used as two of them provided incomplete data. Study I and Study II used the same prison subjects. Due to certain regulations of the State Penitentiary, the researchers were forced to use volunteer prisoners, who were each paid one dollar and who were recruited from the educational programs in the prison. The thirty-eight subjects consisted of nineteen men convicted for violent crimes and nineteen sentenced for non-violent offenses. The non-violent criminals were chosen so that they had no previous convictions for violent crimes. The criteria for determining whether a crime is violent or non-violent is presented in Appendix B.

For Study I, a normative group of non-prisoners was also tested consisting of thirty-eight male students from an introductory psychology class at Portland State University.

Measuring Instrument. The self and ideal-self concepts were measured in Studies I and II with the Interpersonal Adjective Checklist (ICL; see Appendix C). The ICL, developed by Robert Suczek and Rolfe LaForge (LaForge, 1973) in conjunction with Timothy Leary's (1957) work on an interpersonal diagnosis of personality, is an instrument by which an individual describes him or herself and/or ideal-self by checking off appropriate adjectives and phrases (e.g. - able to give orders, usually 
gives in, ixritable, etc.). The resultant ICL grid visually depicts the person using Leary's eight categories of interpersonal style (See Appendix A). Unlike many other personality tests, the ICL describes the person using simple, everyday language rather than psychodiagnostic categories. Many psychological batteries, such as the MMPI, use a highly technical language that only a trained psychologist can understand. The ICL, on the other hand, is in a non-technical language and is thus easily interpreted by the lay individual.

Design of Study I. This study investigated the ICL patterns of the prison group in terms of the variable, type of crime (violent vs, non-violent crimes). The ICL patterns were measured in terms of thirteen scores: the eight octant scores, DOM and LOV (summary scores which place the person on the dominance-submission and love-hate dimensions, respectively), Ain (the average intensity of items checked, which served as a measure of social desirability; LaForge, 1973), Nic (number of items checked, which served as a measure of acquiesence; LaForge, 1973), and the SID score (self-ideal discrepency). For each of these dependent variables, a comparison between the mean score of the violent prisoners and the mean of the non-violent was made. For the octant scores, DOM, LOV, Ain, and Nic, comparisons were done separately for self and ideal-self instruction sets.

Comparisons were also made between the ICL patterns of the prison group as a whole (violent and non-violent combined) and the scores of the student group for self and ideal-self concepts in the same manner as described above.

Design of Study II. The relationship between length of imprisonment 
and the ICL patterns was investigated by correlating time already served for the prison subjects with each of the ICL octant scores, as well as with DOM, LOV, Ain, Nic, and SID. Since length of imprisonment may have conceivably been associated with type of crime (with violent criminals having served more time than the non-violent ones), the effects of type of crime were factored out by performing a partial correlation between length of imprisonment and the ICL scores with the effects of type of crime partialled out. For the octant scores, DOM, IOV, Ain, and Nic, the correlations were performed separately for self and ideal-self instruction sets.

Procedure: The procedures for both studies involved having subjects fill out two ICL forms. The two adjective checklists (self and ideal-self instruction sets) were administered consecutively in one testing session. Subjects were tested in groups as opposed to individual testing. The prisoners made up one testing group and they were tested within the confines of the State Penitentiary. The student subjects (Study I) comprised the other testing group and were administered ICLs in a classroom at portland State University.

Subjects were first given an ICL form with. instructions to check off items which were true of themselves. The following instructions were stapled to each form:

Go through the list and check off all those words and phrases which describe yourself (the way you see yourself at the present time). Leave blank all those spaces next to items which are not descriptive of yourself.

In addition, the examiner read the following instructions after the 
forms had been handed out:

On this form, tear off the instructions and read them to yourself.

Okay, now I will read some further instructions so everything is clear. On this sheet you are to read every word and phrase and place an $X$ next to each item which describs yourself as you presently are. Start in the upper left-hand corner with "Acts important". If you view yourself as a person who generally acts important, then place an $X$ next to this item. If not, leave the space blank. Proceed in this fashion until you have considered every item on the page.

Remember, be sure to look at every item and only check those which describe yourself, leaving all others blank.

Any questions?

After the ICLs with self instructions had been completed by all

subjects, these forms were collected and another form was handed out with

following attached instructions:

Go through the list and check off all those words and phrases which describe your ideal self (the way you would like to be ideally). Leave blank those spaces next to items which are not descriptive of your ideal self.

The following instructions were read for the ideal-self forms:

Again, tear off the stapled instructions and read them to
yourself.
On this sheet, place an $X$ next to items which describe your ideal self, or how you would like to be ideally. For example, look at the second iten in the upper left-hand corner, "Apologetic". If you view apologetic as a characteristic you would like to have - regardless of whether or not you possess this characteristic now - then place an X next to Apologetic. Otherwise, leave the space blank.

Again, I wish to emphasize that you consider every item on the page and check off only those which describe your ideal self, leaving all others blank.

Questions?

The prison subjects were instructed to write on a separate information sheet their crime and the length of imprisonment thus far for that crime, as well as any previous crimes. A separate consent sheet was attached to the information sheet, to which the prisoners signed their 
names. After the data on the information sheet was verified with the prison officials, the consent sheet was detached and thrown away. This was done before the examiners left the prison so that the confidentiality of the prisoners was assured.

The student subjects were asked to report on their ICL self form if they had ever spent time in prison before. None of the subjects used had any previous history of imprisonment. 
CHAPTER V

RESULTS

Study I. Scores for each of the ICL octants, and the sumary scores, DOM, LOV, Ain, were determined for each subject. The self-ideal discrepency (SID) was also determined for each subject. The mean scores for the experimental groups are presented in Tables I and II.

T-tests for each octant and each of the summary scores were performed testing for significant differences between the mean scores of the violent and non-violent prisoners. There were no significant differences for any of the scores for either self or ideal-self instruction sets (Table I).

Differences between the mean scores of the prison and the non-prison groups were tested for in the same manner, and some significant differences were found (Table II). On the self instruction set, prisoners scored significantly lower than the non-prison group on the AP octant $(p<.05)$ and on LOV $(p<.05)$. Prisoners' self scores were significantly higher than the non-prisoner scores on the FG octant $(p<.01)$ and on $A$ in $(p<.01)$.

On the ideal instruction set, prisoners scored significantly lower than the non-prisoners on the HI $(p<.01)$ and on FG $(p<.05)$ octants. Prisoners' ideal Ain scores were significantly higher than the non-prisoners' scores $(p<.05)$.

Study II. The octant scores, DOM, LOV, AIn, Nic, and SID were also used in Study II. A partial correlation was performed between each of 
these scores and the factor, length of imprisonment, with the effects of type of crime partialled out. This procedure was performed for both self and ideal-self scores. T-tests here performed testing for the significance of these correlations. The correlation values are presented in Table III.

For the self instruction set, significant negative correlations were found between length of imprisonment and the LM $(p<.05)$, JK $(p<.05)$, HI $(p<.05)$ and LOV $(p<.05)$ scores.

For the ideal instruction set, a significant positive correlation between length of imprisonment and the DE octant score was found ( $p<.05)$. There was a significant negative correlation between the ideal LOV score and length of imprisonment $(p<.01)$. 
TABLE I

ICL MEAN SCORES FOR VIOLENT AND

NON-VIOLENT PRISONERS

$\begin{array}{llll}\text { Mean - Self Scores } & \text { Mean - Ideal-self Scores } \\ \begin{array}{l}\text { Violent } \\ n=19\end{array} & \begin{array}{l}\text { Non-violent } \\ n=19\end{array} & \begin{array}{l}\text { Violent } \\ n=19\end{array} & \begin{array}{l}\text { Non-violent } \\ n=19\end{array}\end{array}$

Score

$\begin{array}{lrrrr}\text { AP } & 4.63 & 5.16 & 5.42 & 5.05 \\ \text { NO } & 5.73 & 6.63 & 5.63 & 6.68 \\ \text { LM } & 6.58 & 6.79 & 6.52 & 7.74 \\ \text { JK } & 4.37 & 4.89 & 3.89 & 4.42 \\ \text { HI } & 4.47 & 4.53 & 2.84 & 2.89 \\ \text { FG } & 6.32 & 4.89 & 2.32 & 2.74 \\ \text { DE } & 6.89 & 5.74 & 6.26 & 5.0 \\ \text { BC } & 6.42 & 6.16 & 5.37 & 6.11 \\ \text { DOM } & 1.19 & 2.73 & 5.93 & 6.1 \\ \text { IOV } & -2.16 & 1.38 & 1.55 & 4.32 \\ \text { AIN } & 2.13 & 2.04 & 2.02 & 2.01 \\ \text { NIC } & 45.42 & 44.53 & 38.79 & 40.63 \\ \text { SID } & 12.53 & 8.35 & & \end{array}$


TABLE II

ICL MEAN SCORES FOR PRISONERS AND NON-PRISONERS

Mean - Self Scores

Prisoners Non-prisoners $n=38$
Mean - Ideal-self Scores

Prisoners Non-prisoners $\mathrm{n}=38 \quad \mathrm{n}=38$

$\underline{\text { Score }}$

$\begin{array}{lllll}\text { AP } & 4.89 & 6.34 \mathrm{p}<.05 & 5.24 & 5.92 \\ \text { NO } & 6.18 & 6.34 & 6.16 & 6.76 \\ \text { IM } & 6.68 & 7.21 & 7.13 & 6.66 \\ \text { JK } & 4.63 & 5.26 & 4.16 & 5.21 \\ \text { HI } & 4.5 & 4.26 & 2.87 & 4.32 \mathrm{p}<.01 \\ \text { FG } & 5.61 & 3.66 \mathrm{p}<.01 & 2.53 & 3.63 \mathrm{p}<.05 \\ \text { DE } & 6.32 & 5.26 & 5.63 & 4.68 \\ \text { BC } & 6.29 & 5.58 & 5.74 & 5.71 \\ \text { DOM } & 1.95 & 4.18 & 6.02 & 3.99 \\ \text { LOV } & -. .39 & 3.6 \mathrm{p}<.05 & 2.94 & 3.82 \\ \text { AIN } & 2.08 & 1.99 \mathrm{p}<.01 & 2.02 & 1.87 \mathrm{p}<.01 \\ \text { NIC } & 44.97 & 43.08 & 39.71 & 42.87 \\ \text { SID } & 10.44 & 12.67 & & \end{array}$


PARTIAL CORRELATIONS OF IENGTH OF IMPRISONMENT BY ICL SCORES

$\underset{n=38}{n-\text { Self Scores }} \frac{r \text {-Ideal-self Scores }}{n=38}$

Score

\begin{tabular}{|c|c|c|}
\hline$A P$ & .07 & -.055 \\
\hline NO & -.184 & -.106 \\
\hline LM & $-.348 p<.05$ & -.196 \\
\hline $\mathrm{JK}$ & $-.349 \mathrm{p}<.05$ & -.278 \\
\hline $\mathrm{HI}$ & $-.35 \quad \mathrm{p}<. .05$ & -.206 \\
\hline FG & .025 & -.160 \\
\hline $\mathrm{DE}$ & 298 & $.356 \mathrm{p}<.05$ \\
\hline$B C$ & .057 & .207 \\
\hline DOM & .179 & .118 \\
\hline LOV & $-.317 p<.05$ & $-.428 p<.01$ \\
\hline AIN & .028 & .014 \\
\hline NIC & -.20 .5 & -.055 \\
\hline SID & -.117 & \\
\hline
\end{tabular}




\section{CHAPTER VI}

\section{DISCUSSION}

Study I. In general, the results provide some support for the hypothesis that prisoners view themselves as more rebellious and distrustful, less loving and in a less socially desirable fashion than the non-prison group. The difference between the violent and non-violent groups do not achieve significance and there is no one simple conclusion as to this finding. After the analysis of the data other significant and interesting relationships emerged. Therefore, the authors of this research will begin by discussing the specific findings as generated by our hypothesis and then discuss the other significant results deserving attention.

The first three hypotheses concerned various predictions about differences between violent and non-violent offenders. No significant differences were reported and thus, violent prisoners do not appear to differ from non-violent ones. This is supported by much of the literature in which differences were not obtained or were contradictory, and questions those which have obtained differences. Several reasons, however, may account for the results. The use of Wilds' classification appears to have been a poor selection on the part of the researchers. Wilds' division is based on a definition of aggression which relates violent behavior to physical harm and non-violent behavior as that different from physical harm. However, on our testing instrument, the ICL, the individual who engages in physical violence would be diagnosed 
on the interpersonal grid as having an aggressive personality as would others who exhibit their aggressiveness in more subtle but just as effective means (Leary, 1957). This, then, may well account for the result and an ICL with adjectives more sensitive to this difference could be developed, 1.e., enjoys hitting others; enjoys slandering others; enjoys touching others; enjoys gossiping and so on. This sensitivity may only be unique to the prison group and in differentiating these two classifications.

On the other hand, this study could also lend support to the school of thought which finds no differences between the groups. The ICL has been shown to be able to differentiate between psychiatric and non-psychiatric groups. Therefore, the ICL, which has the ability to differentiate between groups, may be indicating that there is no difference between violent and non-violent offenders and that the difference lies between prisoners and non-prisoners, as the data demonstrates.

As hypothesized, the prisoners viewed themselves to be significantly more rebellious and distrustful (FG octant) than the non-prison group. That prisoners would obtain higher self-concept scores on the aggressive-sadistic (DE) octant was not borne out although there was a slight tendency for the prisoners to view themselves as more aggressivesadistic (See Table II). This would tend to support much of the literature as well as the traditional image of a prison group. Also, it should be noted that the rebellious-distrustful octant is most related to criminality when compared to findings of other research measures and thus it was expected for the prisoners to report themselves in this same way. Placement of the aforementioned octants are in the areas of most hate as 
depicted on the ICL grid (Appendix A) and perhaps indicate the extent to which pxisoners see themselves as hateful people and thus probably leading to antisocial behavior - and prison. That the prisoners would have a tendency to view themselves as more competitive and narcissistic and self-effacing and masochistic than the non-prison group was not true and perhaps indicates that the real difference between these two groups is in the hate octants and that the prisoners see themselves as having more of the rebellious and distrustful behaviors than non-prisoners.

When looking at the IOV dimension one would expect the prisoners" self-descriptions to be characterized by less LOV, as they appear to see themselves as more hating than the non-prison group, as just cited above. And this is exactly what happens. The prisoners obtained significantly lower LOV scores than the non-prisoners, lending further support and consistency to the first hypothesis. Less DOM was not found to be true of the prison group, although the prisoners scored significantly lower on the managerial-autocratic octant, which is located in the DOM section of the grid, indicating less assertiveness.

Being that prisoners scored high on the hate octants, which provokes others to respond to them in manners of punishment and rejection and significantly low on the LOV dimension, it could then be expected that they might see themselves as less socially desirable than non-prisoners. This was found to be true for both their self and ideal-self reports. This score has many interesting implications for the prisoners and for rehabilitative purposes. But first it is important to note what this means. The prison group scored significantly above the non-prisoners in the Ain score, indicating that their responses are more intense, in that they 
selected the more maladjusted characteristics in describing both their present selves and ideals (See outer ring on ICL grid). Therefore, they are considered to be the less socially desirable responses. However, it must be understood that the Ain score, or the average intensity of the items checked, is not indicative for each of the octants and can only be viewed as an overall manner of responding. Thus, this suggests that the prisoners were willing to criticize themselves and were being outright and honest in how they viewed themselves and their ideals. It should also be noted that the prisoners were in an educational program and thus are encouraged in learning and exploring and perhaps were able to be even more critical of themselves. This also supports the significant Ain score. Furthermore, they are prisoners and behind bars because they exhibited less socially desirable behaviors. of the three significant differences found comparing the idealself of prisoners to the ideal-self of non-prisoners, the only one that might be construed to be in a less socially desirable direction is the Ain or average intensity of response score.

The prisoner's high ideal Ain score has further implications, for even in his ideal reports he is still viewing himself in a less socially desirable fashion. Thus the prisoners are aspiring to a less socially acceptable person. This could also mean that the prisoners see themselves in their ideal as having more intense feelings than non-prisoners. Therefore, it should be noted that it is not their basic ideals which differ, but perhaps the intensity of these ideals that may lead them to less socially desirable behaviors.

As a result of the data analysis it was also found that prisoners' 
self-concepts were significantly less managerial-autocratic than the non-prison group. Perhaps then, their less assertive self-concepts enabled them to be led in less socially desirable ways which would support the picture of the prisoner as being less assertive. This octant is located in the dominant portion of the ICL grid and would suggest some support for the prediction that prisoners would have less DOM than non-prisoners, although this was not proven to be significant. This could also be alternatively interpreted as the prisoners' inability to be assertive due to the nature of the prison environment.

Another interesting finding was that the ideal-self reports of the prisoners were characterized by less self-effacement and masochism and less rebelliousness and distrustfulness than the non-prison group. The prisoners are responding for these two octants, in the ideal-self report, in the more socially desirable direction. Are the prisoners fooling us or "padding" their responses or are they being truthful? Let us assume that the prisoners are being truthful in their responses. When looking at the rebelilous-distrustful octant on self report, the prisoners have significantly more of these traits than the non-prisoners. Ideally they want to have significantly less rebellious-distrustful traits than the non-prison group want to have. The non-prison group virtually stays the same in their amount of rebellion and distrust for self and ideal-self reports. This change between self and ideal-self may imply that the prisoners want to make an overly necessary change in the amount of rebellious-distrustful characteristics than they have to. This perhaps can lead to frustration and maladjustment and adversely affect the "rehabilitative process". Prisoners are perhaps over-reacting to the amount 
of rebellious-distmustfulness within them wanting to rid themselves of more of these characteristics than necessary.

For the same finding let us assume that the prisoners are not being truthful. To some, prisoners are considered untrustworthy and for this very reason they would give little, if any, significance to this study, as the prisoners were all engaged in self report. However, prisoners who lie would tend to lie in socially acceptable ways because they would feel that it is in their best interest to present themselves in this favorable light. Also, they are assumed to be distrustful and weary of psychological tests. Thus, the large difference in the prisoners' self and ideal-self responses might indicate to some that the prisoners were responding in what they thought were more socially acceptable ideals. Looking at the rebellious-distmustful octant, the ideals perceived by the prisoners are to have less of these traits than the non-prison group. The non-prison group has these same traits in the self report and ideal-self report. The prison group, if you follow the assumption cited above, feels that society wants them to have very little rebellious and distrustful characteristics, which is even less so than the "normal" or non-prison group. For rehabilitative purposes it might be useful for the prisoners to know that they need not rid themselves of this trait as greatly as they feel society wants them to. Also, the self-effacing and masochistic octant shows that the prisoners ideally want to have significantly less of these characteristics than the non-prison group. Taking the other assumption, they have the feeling that society wants them to have less self-effacement and masochism than the non-prisoners. If it is further assumed that 
the non-prisoners are better adjusted, then this large difference between the ideal-self reports of the prisoners and non-prisoners, although in a "socially desirable" direction, is not desirable. Perhaps, then, a certain amount of self-effacement and masochism are necessary to be well adjusted and the prisoners are overreacting by saying that they want to have significantly less masochism ideally than the non-pxisoners.

The Ain score was previously discussed in the light of its significance. However, if it is looked at in the light of the prisoners being non-truthful, it could be theorized that the prisoners would have lower Ain responses as compared to non-prisoners and thus be giving less intense responses which interpret their overall general response pattern to be in the more socially desirable direction. In this way they are presenting a favorable picture of themselves to others. In following this interpretation then, one might say that untruthful responses appear to reflect the way the prisoner perceives the world outside to view how he should be - or simply, how he feels society wants him to be. So, for this assumption, when he lies he is being influenced by what he thinks society wants him to become. So, even if one goes by the assumption that they are "padding" their responses, this information might be useful to know, because the overly intense responses, that the prisoner feels society wants him to make, might be unrealistic. For example, if the prison population responds that they ideally should "love everyone" and they think that this is what society wants them to do, then, they would mark this response as ideally true for themselves. However, this overly intense response is not socially desirable. Therefore, the implications 
of this finding might suggest that the "rehabilitative process" takes into consideration what the prisoners feel society wants them to be. However, the prison group scored high on the Ain scale as compared to the non-prison group. This indicates high intensity responses which may be considered to be maladjusted and less socially desirable. Therefore, prisoners may very well have a warped picture of what "normal" behavior or socially acceptable behavior might be.

In either interpretation, whether the prisoner is answering from society's viewpoint or his own, there exists in their ideal-self concepts an inflated image of what is "ideal" in order to be considered "normal". Thus, it would seem.important for rehabilitative purposes to introduce to the prisoner that it is not necessary nor realistic for him to make or contemplate such profound change and that society does not warrant him to have such high ideals. In other words, the world outside does not want the prison group to become to "love everyone". It is easy now to see how these beliefs could lead to tremendous frustration and numbing of motivation, so preventing their successful re-entry into society.

In summary, it really does not matter whether or not the prisoners are being untruthful because if they are not telling the truth they appear to be responding in the way they see society wanting them to be. Whether the prisoner is saying who he ideally wants to be, or what he thinks society wants him to be, can both give useful information. One problem In the interpretation of the data was that it was not known in what way the prisoner was responding - truthfully or the way he feels society wants him to respond. That is why, in the interpretation of the data both of these possibilities have been explored. 
It would seem that the pxisoners were responding in a critical, truthful manner as indicated by the significant Ain scores, FG self and ideal-self score, HI ideal-self score and because of the knowledge that they are an educated group which had volunteered to partake in such a study and thus are more self-motivated. However, the point must be stressed, that even if the prisoners are not telling the truth, as some might assume from the onset, that useful information can still be gathered when using the ICL.

In order to demonstrate which interpretation is the more valid, a study with the ICL instruction set for the ideal report using the statement "how you would like to be" and "how you feel society wants you to be" should serve to asnwer some of the questions raised in this section.

The ICL appears to be a good assessment instrument for differentiating between prisoners and non-prisoners. However, depending upon the uniqueness of the subjects and the manner in which they have been classified and so studied, it may lack the sensitivity to discriminate between violent and non-violent offenders. This, however, will depend on future research, as previously suggested. The authors of this study are of the opinion that this difference may not exist, as much of the Iiterature concerming the differences between violent and non-violent prisoners is either supportive of the current findings, or has in itself been contradictory.

The ICL appears to measure a meaningful level of the prisoner's personality, and this prisoners can be administered a self report personality assessment measure like the ICL with some useful information resulting. The truth or falsity of the responses is not decisive as 
regards the utility of the instrument for rehabilitative purposes.

The ICL may be most useful rehabilitatively as a comparison for the prisoner against a non-prison group. In this way, it could be demonstrated that his great need of change is perhaps unrealistic as compared to the non-prison group.

The ICL has progressed from its suggested use as a "channel of communication" (LaForge, 1973) as it has permitted us to tap at the interpersonal domain of the personality of prisoners and has served usefully as an instrument for measuring some aspects of personality. Thus, this study has demonstrated the ICL to be a useful research instrument that it can be taken out of the psychotherapeutic environment and into the prison for research purposes.

In summary, there appears to be no significant differences between violent and non-violent offenders as depicted by the ICL. Differences, however, were reported between the prison and non-prison group. That these results are consistent with some findings in the literature suggests that the ICL is able to differentiate between these two groups and that prisoners can also give a useful self report measure of their personality. Generally, the significant differences for the self-concepts include rebellious-distrustful characteristics, assertiveness and the average intensity of responses and for the ideal-self concepts, those traits found in the lower left quadrant of the ICL grid as well as the average intensity of response or social desirability. When summed, these differences could very well explain some of the reasons for the subjects being incarcerated.

The ICL has diagnosed the prison group to be of the rebellious-dis- 
trustful personality type who sees themselves as having to markedly limit these traits in their ideal as compared to the non-prison group. "Untruthful" ideal-self responses do not appear to affect the usefulness of the ICI and it has been suggested that these responses may be interpreted as descriptions from the prisoner's perceived ideal which society holds for him. The prisoner's extreme need to change in the ideal may very well be the factor limiting his re-entry into society and even more so, his motivation to contemplate such change.

The ICL is a simple way of demonstrating what can be secured from an interview with the prisoners. This assessment instrument has no hidden meaning. Its interpretation is straightforward, read from an 'easily understood grid. What the person wishes to communicate is what is explored.

Study II. The most notable finding in terms of the correlations between length of imprisonment and the ICL scores (Table III) is a significant, negative correlation between time served in prison and the idealself IOV scores, substantiating the first hypothesis. In addition, the LOV score was also found to be negatively correlated with time served for the real-self. Prisoners, then, seem to develop more hateful self-concepts and ideals as they spend more time within the prison environment. This conclusion is consistent with the findings of other researchers and with the theories of Goffman and Clemmer.

The correlational nature of this study does not make possible a definite causal explanation as to why prisoners develop self and ideal-self images which are marked by less love. One plausible interpretation of the findings concerning IOV scores, however, is that the 
dehumanizing aspects of the prison environment and the prison experience cause one to seem a more hateful person and view love as a less desirable ego-ideal. Such dehumanizing factors include the restriction of free movement, living communally under the authority of others, rigid dress and eating habits, denial of individual rights, etc. When a person enters a prison, he is faced with the problem of fulfilling his needs and wishes in such a deprived, limited environment. Survival becomes an everyday struggle, and this may lead to the adoption of behavior which is conniving and deceitful. Thus, the prisoner becomes more hateful and views such behavior as a more desirable goal. Aside from the environment itself, the prison social structure is important; it is the way through which the prisoners deal with their problems. By establishing a strong, authoritarian social system, the prison inmates gain solidarity and thus achieve some degree of power. Thus, when one enters a prison, he invariably becomes part of the prison society and eventually adopts the values of that culture. The lowering of the ideal LOV score over time may be due to such a prisonization effect, where criminals, as they become more involved with other criminals, adopt a more anti-social attitude. If this interpretation were true, however, it would be expected that the level of social desirability of response would decrease with time for the ideal-self scores. The second hypothesis stated that Ain (the ICL measure of social desirability of response) would be positively correlated with time, indicating the adoption of anti-social values, but this prediction was not borme out. The Ain score, however, measures social desirability as intensity of interpersonal behaviors which are endorsed, where a low level of intensity reflects a socially desirable response set. This 
definition of social desirability is not precisely the same as Clemmer's idea of anti-sociality. The research which has attempted to verify the existence of Clemmer's prisonization defines anti-sociality as non-conformity to the expectations of the prison staff. Non-conformity to those in a position of authority implies misbehavior or engaging in negativistic behavior; a high Ain score means that a person is willing to admit to both positive and negative interpersonal behaviors which are intense or maladaptive (LaForge, 1973). Thus, it can be concluded that prisonization was operative for the subjects in this study, as indicated by a tendency to adopt hate as a personal ideal, and that the unexpected finding for Ain is due to the dissimilarity between the ICL's definition of "socially desirable" and clemmer's definition of "anti-sociality". That prisonization exists is further supported by a significant, positive correlation between the octant score measuring aggressive-sadistic behavior (DE) and time for the 1deal-self. Prisoners, as they spend more time within the institution and become more a part of the criminal culture, come to view aggressive-sadistic behavior as a more desirable goal, indicating the acceptance of values which deepen criminality.

The LOV score findings, then, suggest that prisoners have a tendency to develop more hateful self and ideal-self concepts as they spend more time within the confines of the prison. Contrary to the third hypothesis, a sighificant negative correlation was found between length of imprisonment and the self score measuring self-effacing-masochistic behavior (HI octant). Thus, the hate that develops within imprisoned criminals over time is not directed inward. The prisoners in this study did not become more self-effacing or self-hating; on the contrary, they exhibited less 
of this type of behavior in their self reports. This finding is not in agreement with other research investigating the impact of imprisonment on self-concepts. Bannister, et al. (1973) also found the development of a less loving attitude as a result of imprisonment, but their findings suggest the emergence of introversion and self-directed hate. This inconsistency may be due merely to sampling differences between this study and that of Bannister et al. Bannister et al. used prisoners from British penal institutions serving determinate sentences of ten years and above or indeterminate sentences, and measured total accumulated imprisonment. The present study did not account for length of sentence and only measured time spent in prison for the most recent conviction. It is conceivable that Bannister's subjects, many of whom probably had longer sentences than the subjects used in this study, were more fatalistic about their future and, therefore, exhibited more inwardly directed hate. Further research is needed to determine the importance of length of sentence. A ratio between time already served and length of time left to serve may be a more desirable way to study the effects of imprisonment on personality and self/ideal concepts.

It must also be stressed that the present study used a rather select group of prisoners, which may further explain the unexpected finding of decreased levels of self-effacing-masochistic self reported behavior over time. Whereas most other research on the personallty of prisoners had used randomly chosen subjects, the authors of this study were forced to use volunteer prisoners who were all enrolled in an educational program of some type. It seems reasonable to assume that the prisoners used as subjects for this study were better educated, more inteliligent, and perhaps 
more self-motivated than the general population of imprisoned criminals. Such a select group, being more perceptive, may be better able to direct their feelings of hate and hostility outward toward the system which has them imprisoned rather than engaging in self-punishing behaviors. This interpretation is given some support by the significant positive relationship between ideal-self aggressive-sadistic behavior (DE octant) and time, and by an almost significant tendency ( $p<.10)$ for prisoners to develop self-concepts which are more aggressive-sadistic. The fact that the latter relationship was not significant, however, means that no definite conclusions can be drawn. Education and intelligence may be important factors, and future research should take them into account.

The final major finding of this study is concerned with the self score for the cooperative-over-conventional (LM) and docile-dependent (JK) octants, scores about which no predictions were made. The significant negative correlations between time served and the IM and JK octants for self-concepts indicate that the prisoners come to view themselves as less passively loving as they spend more time within prison. These two scores make up a quadrant on the ICL grid sometimes referred to as the "good child", reflecting behavior which is friendly and loving but in a submissive or obedient way. As discussed earlier, a person who lives inside a prison is deprived of many basic needs and freedoms which those who live on the outside take for granted. Iiving within such a deprived environment can conceivably cause a person to give up friendliness and cooperativeness. Thus, prisoners become "hardened" as they spend more time within the prison community. This may reflect a survival mechanism, where docile, cooperative behavior is shed and a more hostile attitude is taken on. It 
has already been shown that the prison is not a place conducive to a loving attitude. As mentioned earlier, the prison environment and social structure tend to make survival a struggle, which leads to more deceitfulness and, in turn, less cooperativeness and friendliness. This explanation is given further support, since prisoners have more of a tendency to take on aggressive-sadistic behavior (octant $\mathrm{DE}$ ) as a personal ideal with the passage of time in prison.

In conclusion, it is noteworthy that almost all of the significant findings of this study suggest a strong negative impact of imprisonment on how a person views himself and how he would like to be ideally. The results suggest that not only does a prison inmate seem less loving to himself as he spends more time inside, but that he also adopts hate as an ego-ideal or goal. Prisonization did seem to be operative for the prisoners tested in this study. A closer look at the data indicates that prisoners did not become more self-hating; on the contrary, they exhibit less self-effacing-masochistic behavior in their self-views as time passes. They become more hateful by appearing to themselves as less cooperative and friendly in their self-images and more aggressive-sadistic in their ideals. Although no definite conclusions as to causes can be drawn from this correlational study, it seems likely that the hateful and "hardened" attitude which develops in prison inmates is due to the restrictive, dehumanizing environment as well-as the prevailing social climate which only serves to deepen criminality. The general implication of these findings is that the rehabilitative value of such maximum security prisons as the Salem State Penitentiary is minimal. Such total institutions seem only to have negative effects and do little to improve the criminal's 
self-conception or his values, as Goffman, Glemmer, and others have suggested.

Again, as in Study I, the ICL has proved to be a useful research tool. It has provided relevant information as to how a prisoner's self and ideal-self images change as a function of imprisonment. Taken together, the two interrelated studies of this research point to the ICL as moxe than just a "channel of communication" (LaForge, 1973). As a research instrument, the ICL has not only provided insight into how and why a group withmany interpersonal problems differs from a "normal" population, but also demonstrated how the self and ideals of such a group change over time spent within a total institution. It is hoped that these two studies will spur further acceptance of the ICL as a research instrument for studying groups of all kinds - socioeconomic, racial, religious, professional, etc. - and especially for investigating the intexpersonal dynamics of groups, such as prisoners, who are known to have many interpersonal problems. 
REFERENCES

Abrahamse, David. Crime and the Human Mind. New Jersey: Patterson Smith Co., 1969.

Abrahamse, David. The Murdering Mind. New York: Harper \& Row, Publishers, Inc., 1973.

Atchley, R.C. and McCabe, M.P. Socialization in correctional communities: a replication. American Sociological Review, 33, 1968 (Oct.), $774-785$.

Banister, P.A., Smith, F.V., Heskin, K.J., and Bolton, N. Psychological correlates of long term imprisonment. British Journal of Criminology, 13 (4), 1973 (oct.), 312-330.

Baugham, J. and Pierce, D. MMPI correlates of prisoner's ideal-self. Correctional Psychologist, 5 (3), 1972 (Winter), 195-199.

Berg, Worman. Self-concept of neurotic and sociopathic criminal offenders. Psychological Reports, 34, 1974, 622.

Bieri, James and Lobeck, Robin. Self-concept differences in relation to identification, religion, and social class. Journal of Abnormal and Social Psychology, 62 (1), 1961, 94-98.

Blackburn, R. Personality in relation to extreme aggression in psychiatric offenders. British Journal of Psychiatry, 114, 1968, 821-828.

Brenberg, R.E. An analysis of the responses of a male prison population to the Edwards Personal Preference Schedule. Journal of General Psychology, 62, 1960, 319-324.

Bromberg, Walter. Crime and the Mind. Philadelphia: J.B. Lippincott Co. 1948.

Bromberg, Walter. Crime and the Mind. New York: Macmillan Co., 1965.

Buikhuisen, W. and Hemmel, J.J. Crime and conditioning. British Journal of Criminology, 12 (2), 1972 (April), 147-156.

Carlson, K.A. Classes of adult offenders: a multivariate approach. Journal of Abnormal Psychology, 1972, 79 (1), 84-93.

Carroll, J.L. and Fuller, G.B. An MMPI comparison of three groups of criminals. Journal of Clinical Psychology, 27 (2), 1971 (April), 240-242. 
Clemmer, Donaid. The Prison Community. New York: Holt, Reinhart, \& Winston, 1959.

Cressey, D.R. (ed.). The Prison. New York: Holt, Reinhart, \& Winston, 1961.

Dahlstrom, W.G., Welsh, G.S., Dahlstrom, L. An MMPI Handbook. Minneapolis: University of Minnesota Press, 1960.

Davis, K.R. \& Sines, J.D. An antisocial behavior patterm associated with a specific MMPI profile. Journal of Consulting and Clinical Psychology, $36(2), 1971,229-234$.

Eysenck, H.J. Crime and Personality. Boston: Houghton Mifflin Co., 1964.

Eysenck, S.B.G. and Eysenck, H.J. A comparative study of criminals and matched controls on three dimensions of personality. British Journal of Social and Clinical Psychology, 10 (4), 1971 (Dec.), 362-366.

Ferguson, L.R. Personality Development. Belmont, California: Brooks/ Cole, 1970 .

Fichtler, H., Zimmerman, R., and Moore, R. Comparisons of self-esteem of prison and non-prison groups. Perceptual and Motor skills, 36, 1973, 39-44.

Fitts, W.H. and Hammer, W.T. The Self-concept of Delinquency, Nashville: Counselor Recording \& Tests, 1969.

Giannell, A.S. Psychological need characteristics of four criminaloffender groups. Journal of Social Psychology, 69, 1966, 55-72.

Glaser, D. and Stratton. Measuring inmate change in prison. In The Prison, by D.R. Cressey (ed.), New York: Holt, Reinhart, and Winston, 1961.

Glover, Edward. The Roots of Crime. New York: International Universities Press, Inc., 1960.

Godfrey, E.A. The average offender. Correctional Psychologist, 1971, $4(4), 153-163$.

Goffman, Erving. Asylums. New York: Anchor Books, Doubleday \& Company, Inc., 1961.

Gynther, M.D. and McDonald, R.L. Personality characteristics of prisoners, psychiatric patients, and student nurses as depicted by the Leary system. Journal of General Psychology, 64, 1961, 387-395. 
Gynther, M.D., Miller, F.T., and Davis, H.T. Relationship between needs and behavior as measured by the EPPS and ICL. Journal of Social Psychology, 57, 1962, 445-451.

Hartung, S., Hartung, J., and Baxter, J, Self and ideal-self concepts in a drug-using subculture. Journal of Personality Assessment, 35 (5), 1971, 463-471.

Hoghughi, M.S. and Forrest, A.R. Eysenck's theory of criminality, British Journal of Criminology, 10, 1970, 240-254.

Horn, J.B. A comparison of robbers, burglars, and forgers on the EPPS. Unpublished Masters thesis, University of Washington, Seattle, 1956.

Howell, I.M. Clinical and research impressions regarding murder and sexually perverse crimes. Psychotherapy and Psychosomatics, 21, $1972 / 73,156-159$.

Kluckhohn, C. and Murray, H. (eds.). Personality in Nature, Society, and Culture, New York: Alfred A. Knoph, Inc., 1949.

Kodman, F. and Hopkins, R.W. MMPI profile characteristics of Kentucky prison inmates. Correctional Psychologist, 1970, 4 (1), 7-10.

IaForge, Rolfe, Using the ICL, Unpublished manuscript, 1973.

Leary, Timothy. Multilevel Measurement of Interpersonal Behavior. Berkeley: Psychological Consultation Service, 1956.

Leary, Timothy. Interpersonal Diagnosis of Personality. New York: The Ronald Press Company, 1957.

Lester, D., Perdue, W.C., and Brookhart, D. Murder and the control of aggression. Psychological Reports, 34, 1974, 706.

Megargee, E.I., Cook, P.E., and Mendelsohn, G.H. Development and validation of an MMPI scale of assaultiveness and overcontrolled individuals. Journal of Abnormal Psychology, 72, 1967, 519-528.

Megargee, E.I. and Mendelsohn, G.A. A cross validation of twelve MMPI indices of hostility and control. Journal of Abnormal and Social Psychology, 65, 1962, 431-438.

Perdue, W.C. and Lester, D. Raclal differences in the personality of murders, Perceptual and Motor Skills, 38, 1974, 726.

Pishkin, V. and Thorne, F. A factorial study of existential state reactions, Joumal of Clinical Psychology, 29 (4), 1973 (Oct.), 392-402. 
Rogers, Carl R. A theory of therapy, personality, and interpersonal relationships. In S. Koch (ed.), Psychology: A Study of Science. Vol. III, New York: McGraw-Hill, 1959.

Royce, J.R. The Encapsulated Man. New York: Litton Educational Publishing, Inc., 1964.

Rulla, L.M. and Maddi, S.R. Personality and the Catholic religious vocation: self-conflict in male entrants. Journal of Personality, 40 (4), 1972 (Dec.), 564-587.

Silverman, R.E. Psychology. New York: Meredith Corporation, 19 ?l.

Sykes, G.M. The Society of Captives. Princeton University Press, 1958.

Tittle, C.R. Institutional living and self-esteem. Social Problems, $20(1), 1972,65-77$.

Wheeler, S. Socialization in correctional communities. American Sociological Review, 26, 1961 (oct.), 699-712.

Wilds, C.E. Evaluation of a method of predicting violence in offenders. Criminology: An Interdisciplinaxy Journal, 11 (3), 1973 (Nov,), 427.

Wilson and Maclean. Personality attitudes and humor preferences of prisoners and controls. Psychological Reports, 34, 1974, 847-854.

Winer, B.J. Statistical Principles in Experimental Design. McGraw-Hill Books Company, 1961.

Yarvis, R. A classification of criminal offenders through use of current psychoanalytic concepts. Psychoanalytic Review, 59 (4), 1972/73 (winter), 549-563.

Zimbardo, P.G. and Ruch, F.L. Psychology and Life (9th edition). Glenview, IIlinois: Scott, Foresman \& Company, 1975. 
SFA ICNEddV 


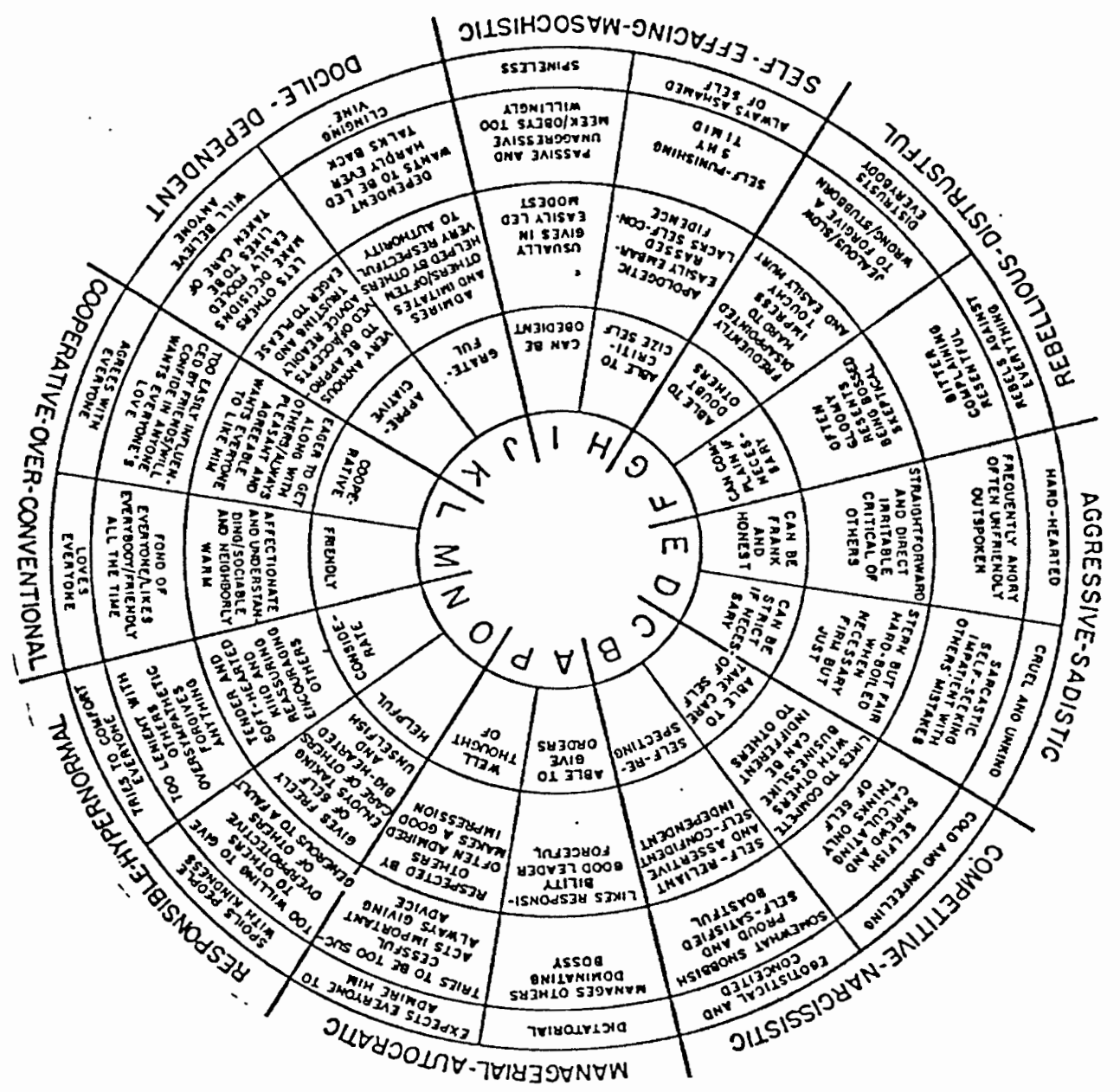

๙บญり TDI

Y XIGNभAddY 
APPENDIX B

\section{CLASSIFICATION OF CRIMES}

Violent Crimes

1. All forms of criminal homicide

2. Rape (not statutory)

3. Robbery

4. Assault and battery

5. Resisting arrest with the use of force

6. Kidnapping-abduction

7. Arson
Non-violent Crimes

1. Burglaries

2. Shoplifting, larceny, theft, (cars included)

3. Forgery, uttering, counterfeiting

4. Embezzlement, cheating, fraud

5. Buying, receiving and possession of stolen property

6. Vagrancy, drunkeness, gambling

7. Corruption of morals of a minor, sodomy, adultery, fornication, bastardy, public indecency, statutory rape, maintaining a house of prostitution

8. Narcotics, liquor and drug law offenses

9. Disorderly conduct

10. Traffic and motor vehicle law violators

This classification system is from Wilds (1973). 
APPENDIX C

INTERPERSONAL CHECKIIST

Acts important

Apologetic

Appreciative

Bitter

-Boastful

Bossy

Businesslike

Complaining

- Considerate

- Cooperative

Dependent

Dictatorial

Dominating

Easily fooled

_Easily led

Firm but just

Forceful

Friendly

Good leader

Grateful

Hard-hearted

Helpful

Independent

Irritable

Jealous

Meek

Modest

- Often admired

Often gloomy

-Outspoken

Resentful

Sarcastic

Self-confident

Selfish

- Self-punishing
Able to criticize self Able to doubt others Accepts advice readily $\mathrm{Able}$ to give orders Agrees with everyone

Always ashamed of self Always giving advice Can be obedient clinging vine Cold \& unfeeling

Critical of others Cruel \& unkind Distrusts everybody Easily embarrassed Encourages others

Fond of everyone

Forgives anything

Frequently angry

Friendly all the time

Generous to a fault

Gives freely of self

-Hard to impress

Kind \& reassuring

Lacks self confidence

Likes everybody

Likes responsibility

Iikes to compete

Loves everyone

Manages others

often unfriendly

Oversympathetic

Resents being bossed

Respected by others

Self-respecting

Somewhat snobbish
Able to take care of self Admires \& imitates others Affectionate \& understanding Always pleasant \& agreeable Big-hearted \& unselfish

Can be frank \& honest

Can be indifferent to others

Can be strict if necessary

Can complain if necessary

Eager to get along with others

Egotistical \& conceited

Enjoys taking care of others

Expects everybody to admire him

Frequently disappointed

- Hardboiled when necessary

Hardly ever talks back

-Impatient with others' mistakes

Lets others make decisions

Likes to be taken care of

- Makes a good impression

Obeys too willingly

Often helped by others

Overprotective of others

Passive \& unaggressive

- Proud \& self-satisfied

Rebels against everything

Self-reliant \& assertive

Shrewd \& calculating

Slow to forgive a wrong

Sociable \& neighborly

Spoils people with kindness

Straightforward \& direct

Too easily influenced by friends

Too lenient with others

Too willins to give in to others 


\section{APPENDIX C (cont.)}

Self-seeking

Shy

Skeptical

Spineless

Stubborn

Tender

Timid

Warm
Stern but faix

Thinks only of himself

Touchy \& easily hurt Usually gives in

Wants everyone's love

Wants to be led

Well thought of

Will believe anyone
Tries to be too successful

Tries to comfort everyone

Trusting \& eager to please

- Very anxious to be approved of

— Very respectful to authority

Wants everyone to like him

will confide in anyone 